\title{
Hour Times Micromole Per Liter Per Kilogram
}

National Cancer Institute

\section{Source}

National Cancer Institute. Hour Times Micromole Per Liter Per Kilogram. NCI Thesaurus.

Code C112304.

Hours times micromoles per liter, divided by kilograms. 